\title{
허리복대와 테이핑이 균형능력에 미치는 영향
}

\author{
명정호 ${ }^{1}$, 양경한 ${ }^{2}$, 이상설 ${ }^{2}$, 박정서 ${ }^{2}$ \\ ${ }^{1}$ 대전보건대학교 방사선과, ${ }^{2}$ 대전과학기술대학교 물리치료과
}

\begin{abstract}
The Effects of Abdominal Belt and Taiping on balance ability
Jeung-Ho Myung ${ }^{1}$, Kyung-Han Yang ${ }^{2}$, Sang-Seol Lee ${ }^{2}$, Jung-Seo Park ${ }^{* 2}$

'Department of Radiological Science, Deajeon Health Institute of Technology

${ }^{2}$ Dept. of Physical Therapy, Daejeon Institute of Science and Technology
\end{abstract}

Purpose The purpose of this study was to investigate the effect of taping therapy and abdominal belt through the one leg standing on balance ability. The results can be used as basic value for studying of relative between balance ability and low back pain. Methods The subjects in this study were recruited 20 students at D college in D community, they were performed one leg standing after attached tape and wearing abdominal belt respectively. The program of diagnosis in postural balance training system (I Balance, Cybermedic Co., Korea) was used to evaluate of balance and performed three times. The effect values were used mean value of that and statistical package for Social Science (SPSS) version 12 statistical software (IBM Co., Armonk, NY, USA) used in performance of all statistical analyses, statistical significance was set at 0.05 . Results The mean value of one leg standing balance in taping group was better than abdominal belt group. The values of COG and dynamic perturbation were significant lower in taping group than abdominal belt group. Conclusion The taping therapy and abdominal belt was effected in trunk stability and taping therapy was more effected on balance ability, COG and angular speed during one leg standing than abdominal belt.

Key Words Abdominal belt, Taping, Balance ability

Corresponding author Jung-Seo Park (pjs2015@dst.ac.kr)

Received date 18 September 2017

Revised date 7 October 2017

Accepted date 13 October 2017

\section{I. 서 론}

성인들이 겪는 질환 중 감기 다음으로 흔한 질병인 요통은 직 장인들이 결근을 하거나 조퇴하는 가장 많은 원인이 되고 있기 때문에 개인의 건강문제 뿐 아니라 사회적인 측면에서도 중요 하게 인식되고 있는 문제이다. ${ }^{1)}$

요통의 원인인 허리부 근력 약화 및 손상은 자세균형을 조 절하는 중요한 생리적 기전을 방해할 수 있어 ${ }^{2}$ 균형 조절 능력 의 감소 및 장애 ${ }^{3)}$ 를 가져오고 요통으로 인한 균형능력이 감 소되면 자세동요와 편측으로 체중 지지를 하는 자세 비대칭성 이 나타난다. 또한 체중심의 이동하는 능력과 위치를 조절하는 능력이 감소되어 불안정한 자세조절의 문제가 나타나게 된다."

균형은 넘어짐 없이 체중을 지지한 자세에서 움직일 수 있 거나 유지할 수 있는 능력을 말하며) 아주 작은 변화일지라도

doi : http:dx.doi.org/10.17817/2017.10.07.111195
몸 전체의 긴장도를 수정하여 이에 대응하는 능력을 의미한다. 균형 조절에 영향을 미치는 요인으로는 안정성의 제한, 근골격 계의 부조화, 가동성의 저하를 포함하는 근골격계 요인과 감각 처리 기능의 저하, 운동출력 기능의 저하를 포함하는 신경학적 요인으로 나눌 수 있닥)

요통을 호소하는 환자들에게 보완요법의 하나로 많이 사용 하는 것이 척추교정술, 마사지, 수지침, 요가 명상, 단전, 테이 핑요법 등 다양하게 시도되고 있으며 만성요통을 호소하는 환 자의 $91.7 \%$ 에서 보완요법을 경험했다고 보고되고 있다. ${ }^{8)}$ 특히 치료 도구인 테이핑이 최근 들어 물리치료사에 의해 광범위하 게 사용 되고 ${ }^{9}$, 서구를 중심으로 약물, 주사, 수술 요법보다는 자연 대체의학, 보완 대체 의학 분야에 눈을 돌리는 경향이 두 드러지면서 테이핑요법이 주목을 받고 있다. ${ }^{10)}$ 그리고 허리복 대 또한 안정화를 제공하기 위하여 임상에서 활용되고 있으며 간편하게 허리에 착용함으로써, 허리의 안정성 향상과 균형능 력 증진 및 허리질환과 관련된 증상에서 통증을 유의하게 감소 
시키는 데 효과적이기 때문에 주목을 받고 있다. ${ }^{11)}$

테이핑요법은 일반적으로 협력근과 길항근의 과활동성억제, 비활성화된 협력근의 촉진, 고유수용감각 자극의 증진, 관절 정 렬의 최적화, 과민한신경 조직에 대한 부하 감소, 그리고 통증 경감을 위하여 적용되고 있으며. 자세균형을 조절하고 평형 능 력을 향상시키기 위해서도 테이핑 요법이 사용되고 있다. ${ }^{12)}$

허리복대는 아랫배와 허리엉치뼈 뒷면을 비 탄력성 밴드로 감싸듯이 고정시키는 것으로, 허리 내압을 높여 신체의 무게를 지지해주거나 외부 충격으로부터 허리를 보호하는 것이 주된 쓰임새다. 특히, 아랫배의 내압, 허리 엉치뼈 근막의 긴장감 및 엉치엉덩관절의 안정성을 강화시켜 척추 안정화에 도움을 준다 고 하였다. ${ }^{13)}$ 또한, 허리복대는 일상생활 동작 중에도 지속적 으로 척추에 안정화 효과를 줄 수 있는 장점을 가지고 있다.

그러나 이러한 허리복대와 테이핑의 간편성과 기능성에도 불구하고 직접적인 몸통 안정화 능력과 관련된 연구는 한정적 인 실정이다. 이에 본 연구에서는 근육의 불균형, 불안정한 관 절과 신경조절에 널리 사용되고 있는 방법인 테이핑요법과, 일 상생활동작 중에 지속적으로 안정화 효과를 유도하는 허리복대 를 통해 한발서기 동작 수행 시 균형능력에 미치는 영향을 알 아보고 향후, 균형능력과 요통과의 관련 연구에 기초자료로 활 용하고 자 한다.

\section{II. 연구방법}

\section{1. 연구대상}

본 연구는 대전소재 대학에 재학 중인 건강한 20 대 성인 중 연구목적과 연구방법을 충분히 설명하고 동의한 20명(남자 10 명, 여자 10명)을 대상으로 실시하였다.

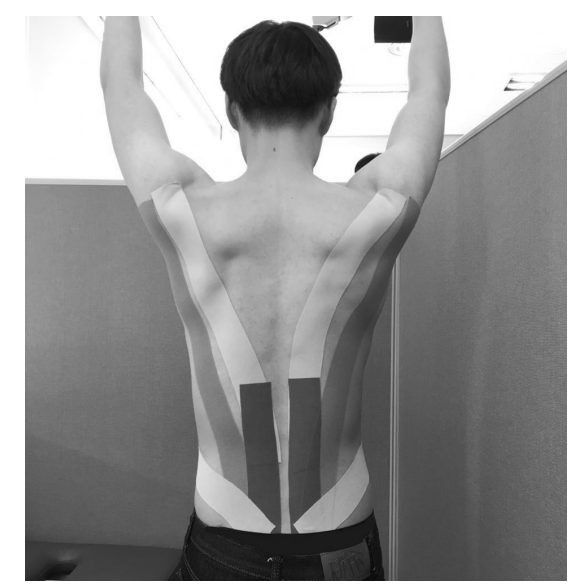

Figure 1. Muscle of taping

\section{2. 연구도구}

1) 탄력 테이프

본 연구에 사용된 탄력테이프는 탄력이 있는 천에 접착 처리한 테이프로 약물 처리가 전혀 없으며 수수한 테이프의 탄력성과 붙이는 방법에 의하여 효과를 발의하는 테이프로 넓이 $5 \mathrm{~cm}$ 의 한국형 $\mathrm{BB}$ tape를 사용하였다. 테이핑요법에 적용된 근육은 넓은등근, 척추세움근, 어깨세모근 아래섬유, 배바깥빗근이다 (Figure1).

\section{2) 허리 복대}

본 연구에 사용된 허리 복대는 (주)닥터서플라이에서 만들어지 진 제품으로 신축성이 있고 폴리에스테르의 재질로 만들어진 medium size을 사용하였다.

복대의 특성에 따른 영향을 배제하기 위하여 각 측정마다 동일 한 것을 사용하였다(Figure2).

\section{3) 균형능력 측정 장비}

자세균형 훈련 시스템(I Balance, Cybermedic Co., Korea) 의 '진단프로그램0'을 사용하였다. 이 시스템은 4 개의 로드셀 (load cell)을 이용하여 신체 동요에 따른 압력 중심(center of pressure, COP)의 변화를 측정하는 방식으로 자세균형 정 보를 분석할 수 있다. 막대그래프 값은 초당 움직이는 각도를 의미하며 평가 중에 COG 정렬상의 노란색 공의 흔들리는 정 도를 각속도라는 단위이다. 몸통의 안정화와 균형능력이 좋은 사람일수록 한발서기 시 몸의 흔들림이 적게 나타나는 것이며, 막대그래프가 낮을수록 몸통의 안정화와 균형능력이 향상된 것 이라고 해석된다.

\section{3. 측정방법}

일반적인 측정 자세는 오른발로 지지하고, 시각차단 후 손과

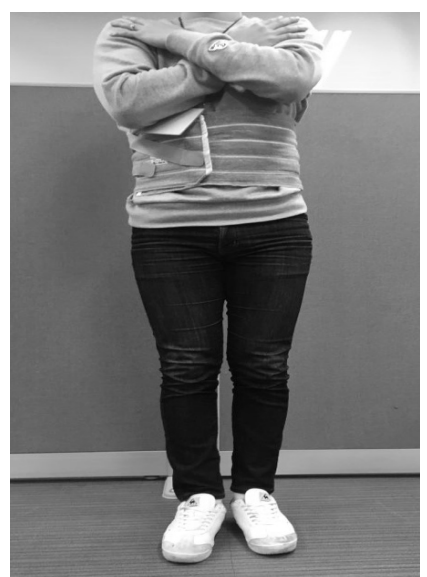

Figure 2. Lower trunk belt 
팔은 몸통을 감싸며 한발서기를 수행하였다. 20 명의 동일한 실 험자들에게 하루씩 간격을 두어 실험하였다. 첫째날은 한발서 기, 둘째날은 테이핑 부착 후 한발서기, 셋째날은 복대를 착용 한 후 한발서기를 실시하였다. 마찬가지로 균형능력 측정 장비 를 이용하여 똑같은 방법으로 균형능력을 측정하였다. 각각의 값은 3 회씩 측정하여 평균을 통계처리 하였다.

1) 편평한 바닥에서 균형능력 측정

대조군과 테이핑을 붙인 군, 몸통에 복대를 착용군 총 3 가지 그 룹으로 나누어 연구를 실시하였다(Figure3)(Figure4)(Figure5).

2) 균형능력 장비의 측정

균형능력 측정 장비에 올라가서 세 그룹별로 균형능력을 측정

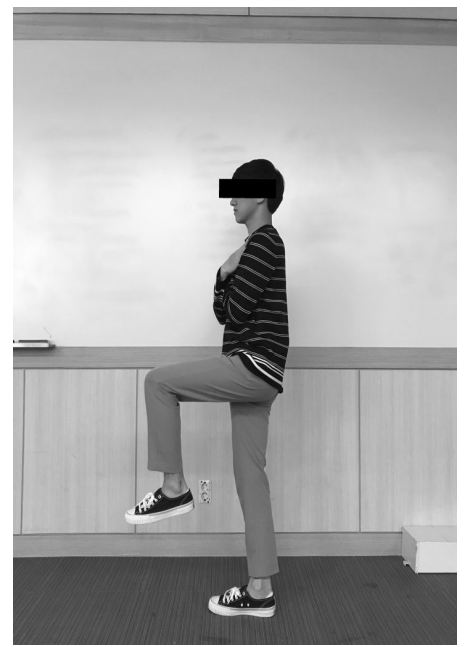

Figure 3. One leg standing on flat surface-side

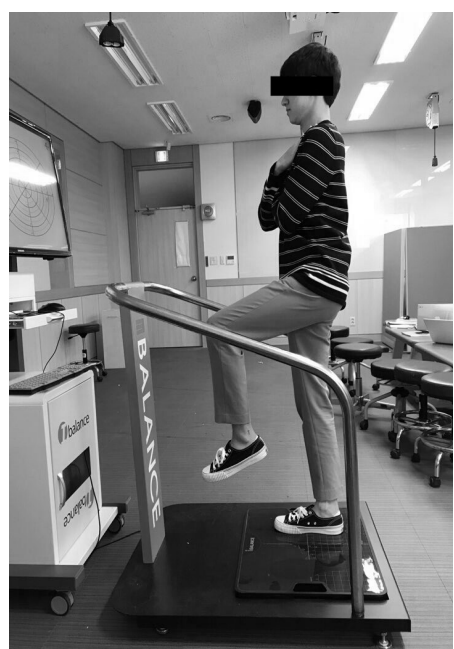

Figure 6. One leg standing on equipment

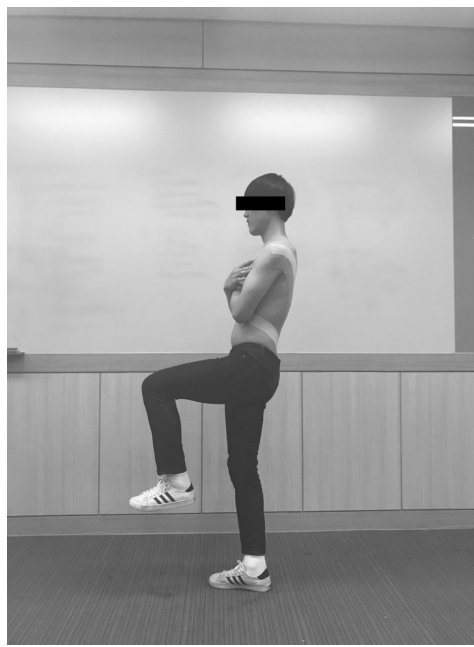

Figure 4. Tape attachment-side

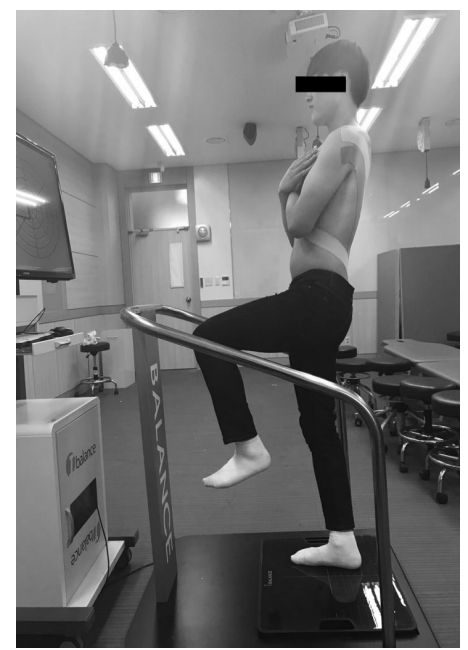

Figure 7. Tape attachment on equipment

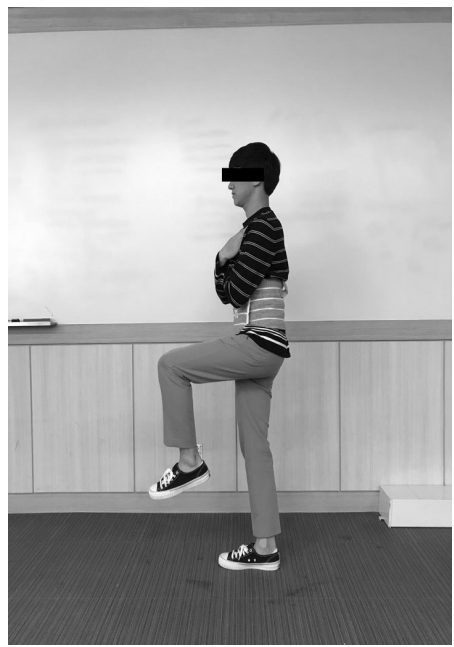

Figure 5. Wearing abdom-inal belt

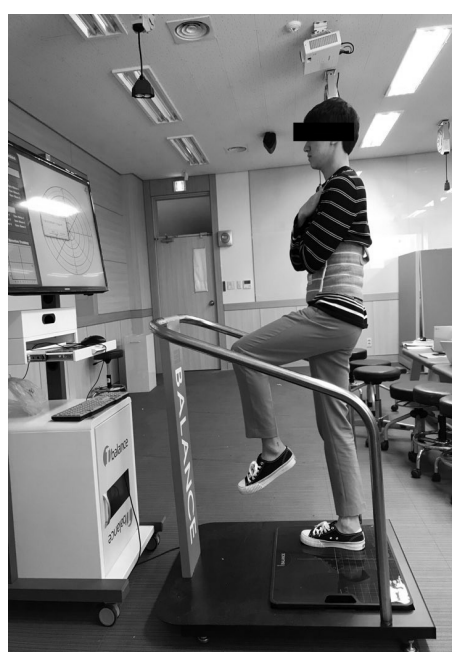

Figure 8. Wearing abdo-minal belt on equipment 


\section{III. 결과}

\section{1. 한발서기 균형 값}

편평한 바닥에서 시각 차단 후 한발서기 수행 시 측정된 평균 초 값은 대조군 $25.8 \pm 22.8$ 초, 복대착용군 $41.5 \pm 36.7$ 초, 테이 핑 부착군 평균 $81.1 \pm 68.9$ 초로 테이핑 부착군이 한발서기지지 시간이 가장 길었으며, 다음으로 복대착용군이였다(table1).

\section{2. $\mathrm{COG}$ 변화 값}

균형능력 측정 장비로 시각차단 후 한발서기를 통해 얻은 $\mathrm{COG}$ 값은 대조군 $56.31 \pm 40.03$, 테이핑 부착군 $41.28 \pm 38.02$, 복대착용군 $50.31 \pm 38.92$ 로 측정되었다. 이와 같은 결과는 $\mathrm{BOS}$ 안에서 흔들리는 $\mathrm{COG}$ 의 범위를 나타낸 것으로 숫자가 클수록 한발서기 시 몸통의 많은 움직임이 발생한 것이다. 3 그 룹 중 테이핑의 COG값이 가장 낮게 측정되었다(table2).

\section{3. 균형능력 장비 동적 흔들림 결과}

막대그래프 값은 초당 움직이는 각도를 의미하는 것으로 막대 그래프가 낮을수록 몸통의 안정화와 균형능력이 향상 된 것 이 라고 해석된다. 본 연구에서는 대조군 4.663 , 테이핑 부착군 2.337 , 복대착용군 3.546 으로 테이핑 시 신체 분절의 움직임 각도 값이 가장 낮게 측정되었다(figure9).

\section{IV. 고찰}

본 연구는 테이핑요법과, 허리복대를 통해 한발서기 동작 수행 시 균형능력에 미치는 영향을 알아보기 위하여 대전지역 20명 의 건강한 성인 남녀를 대상으로 한발서기의 균형 능력을 평가 하였다.

근력은 몸통의 안정성과 구조적 안정성을 제공하는 구조물 로 근육군의 운동성과 유연성을 증가시켜서 신경계와 근육계의

\section{Right E-C(deg/sec)}

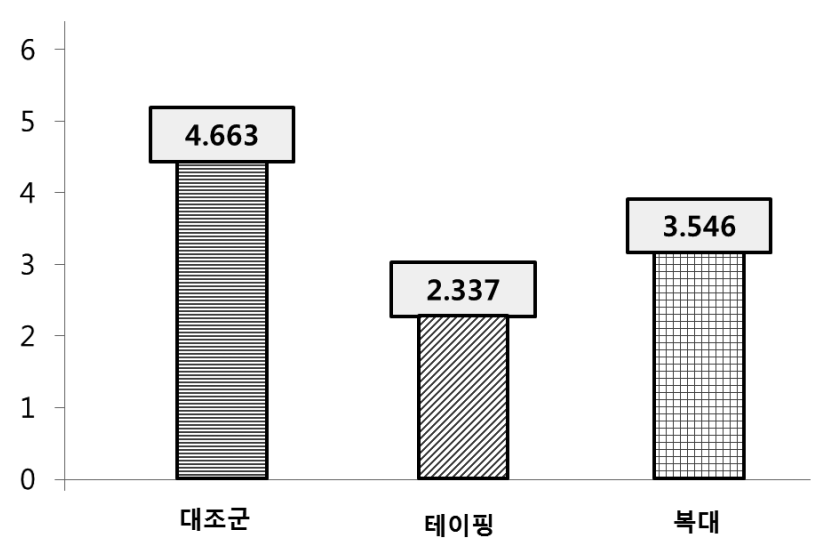

Figure 9. The results of dynamic perturbation

협응과 균형을 발전시키는데 필수적인 것으로, 균형이 좋을수 록 자세 유지에 좋은 영향을 미치는 것으로 알려져 있다. ${ }^{14)}$

김수형 ${ }^{15)}$ 은 만성허리통증 환자에게 적용한 테이핑이 허리 의 폄 근력 향상에 유의한 영향을 미쳤다고 보고하였으며, 장 범철 ${ }^{16}$ 은 허리근육의 약화를 가진 사람을 대상으로 키네시오 테이핑요법을 적용한 결과 허리관절의 앞쪽 굽힘과 가쪽 굽힘 의 가동범위를 증가시켰고, 오랫동안 정적인 자세를 유지하는 특정 직업군인 버스 운전기사를 대상으로 척추세움근에 테이핑 을 적용한 실험에도 유연성이 증가하였다. ${ }^{17)}$ 이는 테이핑 요법 이 일상생활을 영위해 나가는데 있어 유연성 향상에 긍정적인 효과를 주며, 본 연구와 관련지어 볼 때, 테이핑을 통한 근력 향상과 유연성의 증진이 몸통 안정화를 비롯한 균형능력 증진 에 효과가 있었다는 본 연구 결과를 뒷받침한다고 볼 수 있다.

허리 근육을 지지하기 위해 보강장비를 착용한 연구에서는 척추세움근에 근활성도가 감소하였고, 바깥빗근과 배곧은근에 서 활성도의 증가를 보였다. ${ }^{16)}$ 또한 정기용 ${ }^{18)}$ 등은 한발서기 시 테이핑이 몸통안정화에 미치는 근활성도 분석 연구 결과에서도

Table1. One leg standing on flat surface

\begin{tabular}{|c|c|c|c|c|c|c|}
\hline & \multicolumn{3}{|c|}{ mean $\pm S D$} & \multicolumn{2}{|c|}{ Frideman } & \multirow{2}{*}{$\begin{array}{l}\text { Wilcoxon } \\
\text { post-hoc }\end{array}$} \\
\hline & Control & Taping & Belt & $x^{2}$ & $\rho$ & \\
\hline $\begin{array}{l}\text { Time } \\
\text { (sec) }\end{array}$ & $25.8 \pm 22.8^{* \prime}$ & $81.1 \pm 68.9^{*}$ & $41.55 \pm 36.7^{*}$ & 13.3 & $0.001^{*}$ & Control $>$ Belt $>$ Taping \\
\hline
\end{tabular}

Table2. Comparison of COG and balance ability with eye closed

\begin{tabular}{|c|c|c|c|c|c|c|}
\hline & \multicolumn{3}{|c|}{ mean $\pm S D$} & \multicolumn{2}{|c|}{ Frideman } & Wilcoxon \\
\hline & Control & Taping & Belt & $\chi^{2}$ & $\rho$ & post-hoc \\
\hline $\mathrm{COG}$ & $56.3 \pm 40.0$ & $41.3 \pm 38.0$ & $50.31 \pm 38.9$ & 13.3 & $0.001^{*}$ & Control $>$ Belt $>$ Taping \\
\hline
\end{tabular}


바깥빗근, 허리네모근, 큰볼기근, 작은볼기근에 테이핑 후 근활 성도의 유의한 감소를 보였다. 안정화 테이핑을 통한 긍정적인 결과와 근육에 부착된 테이프의 압박, 당겨짐, 늘어짐 등의 역 학적 자극에 따른 생리적 반사의 효과를 통한 근력과 유연성을 증가 시켰다. ${ }^{19}$ 이는 테이핑이 일상생활을 영위해 나가는데 있 어 근력향상과 가동범위 증가 및 유연성 향상에 긍정적인 영향 을 미치는 것으로 볼 수 있다. 본 연구와 관련지어 볼 때, 테이 핑을 통한 근력 향상과 유연성 증진이 허리의 근력증가와 균형 능력 향상에 기여할 수 있으며 본 연구의 결과에서도 테이핑 적용군이 편평한 바닥에서 한발서기 측정값과 균형능력 측정 장비로 시각차단 후 한발서기를 통해 얻은 COG값이 다른 2 군에 비하여 향상된 것은 테이핑요법이 균형능력의 향상에 도 움이 된다고 할 수 있다.

이지은 ${ }^{20}$ 등은 허리복대는 임상적으로 엉치엉덩관절 통증 환자들을 치료하는데 있어서 허리복대 사용이 효과가 있었으 며, 허리복대의 착용 전, 후 정적균형검사와 동적균형검사에서 한발서기검사, 흔들림 균형검사(Y 균형 검사)에서 유의하게 증 가된 결과를 보였고, 균형 과실 점수 시스템에서는 유의하게 감소된 결과가 나타났다.

장현정 ${ }^{21)}$ 등은 허리복대를 착용하여 흔들림 균형검사를 실 시하였을 때, 배속빗근과 뭇갈래근의 근활성도 변화율은 허리 복대를 착용했을 때보다 감소하였다. 박형기와 김택훈 ${ }^{22}$ 은 허 리복대의 착용 후 물건 들기 시 척추사이에 가해지는 내부 압 력을 감소시켜 척추세움근의 활동전위가 유의하게 감소된다고 하였다. 본 연구에서도 허리복대가 한발서기 시 몸통 안정화에 긍정적인 영향을 끼친 것은 근활성도의 감소와 함께 운동 형상 학적 변화에 따른 결과로 해석할 수 있다.

\section{V. 결 론}

본 연구는 대전지역 20 명의 건강한 남녀를 대상으로 테이핑요 법과, 허리복대를 통해 한발서기 동작 수행 시 균형능력에 미 치는 영향을 알아보기 위하여 실시되었다.

한발서기 수행 시 균형유지 시간 측정 및 균형능력 측정 장비를 활용하여 얻은 균형 활성도 결과를 수집하여 분석한 결 과 테이핑과 허리복대가 한발서기 시 몸통 안정화에 긍정적인 영향을 미친것을 확인할 수 있었다. 특히 테이핑이 허리복대 보다 시간적으로 오랜 시간 한발서기를 할 수 있었고, 균형적 인 측면에서도 $\mathrm{COG}$ 값과 동적움직임 각속도 값이 유의한 감소 를 보였다. 따라서 몸통안정화 운동 시 테이핑을 함께 적용하 기를 추천한다.

본 연구의 제한점은 연구 기간이 짧아 테이핑과 복대의 적 용시간에 한계가 있었고, 대상자의 수가 20명밖에 되지 않아 적
은 표본으로 연구했다는 제한점이 있었기 때문에 다수에게 일반 화하기에는 어렵다. 향후 더 많은 표본을 대상으로 연구되어져 야 할 것이며, 충분한 연구 기간을 설정해야 할 것이라 생각된 다. 이후 연구에서는 몸통안정화에 대한 슬링, 짐볼 등을 이용 한 다양한 변수를 적용해 보는 것도 좋을 것이라고 생각한다.

\section{References}

1. Park JY. Nonsurgical management of chronic low back pain. Journal of the Korean Medical Association. 2007;50(6):507-22.

2. Lee HS. Study of standing balance control between normal subjects and subjects with low back pain. Department of Rehabilitation Science Graduate School, Taegu University. 2001.

3. Yang DJ. A study of static standing balance and dynamic standing balance with low back paing. Department of Physical Therapy, Graduate School of Public Health, Daebul University. 2003.

4. Song CH. Effects of extension exercise and flection exercise on the standing position of elderly chronic low back pain patients. Korea sport research. 2007;18(4): 347-56.

5. Nichols DS, Miller L, Colby LA, et al. Sitting balance : its relation to function in individuals with hemispheres. Arch Phys Med Rehabil. 1996;77:865-9.

6. Shumway-Cook A, Anson D, Haller S. Postural sway biofeed back: Its effect on reestablishing stance stability in hemiplegic patients. Arch Phys Med Rehabil. 1988;69(6):395-400.

7. Lee HS, Choi HS. Kwon OY. A Literature review on balance control factors. Physical Therapy Korea. 1996;3(3):82-91.

8. Kim YB. A Study on uses of the complementary therapies in patients with low back pain. Graduate School of Education Yonsei Univercity. 2003.

9. Seo BD, Jung NJ, Park SW, et al. The Effect of a kinesion taping on Muscle Power and Fatigue Index in Quadriceps femoris. Journal of Korean academy of orthopaedic manual therapy. 2011;17(1),29-34.

10. Kim YS, Lee HJ. The effect of isokinetic muscle power and endurance by appling taping femoral knee Joint. Korea sport research. 2004;15(1):805-13.

11. Kim SH, Pak MH, Sim JA, et al. Effects of pelvic compression belt on the thickness of transversus abdominis during active straight leg raising in healthy 
subjects. Journal of Korean academy of orthopaedic manual therapy. 2011;17(1):15-23.

12. Ryu WJ, Kim DM, Kim ES, et al. Effects of taping for ankle and strengthening exercise of hip abductor with thera band on static balance of girls soccer player in elementary school. Journal of Korea Society for Neurotheapy. 2015;19(2):5-12.

13. Pel JJ, Spoor CW, Goossens RH, et al. Biomechanical model study of pelvic belt influence on muscle and ligament forces. J biomech. 2008;41(9):1878-84.

14. Woo JU. The effect of balance in low correction of chiropractic. Dept. of Physical Education. Graduate School Myongji University. 1990.

15. Kim SH. The effect of kinesio taping for low back extensor strengthening and trunk balance in chronic low back pain patients. Department of Rehabilitation Public Health Graduate school of Public Health Gachon University of Medicine and Science. 2007.

16. Jang BC, Kim GH. The Effects of Kinesiotaping on the Flexibility and Maximum Muscle Strength. Special physical education. 2010;7:21-38.

17. Park MC, Kim EY, Ha MS. Effects of taping therapy by methods on back pain and muscle flexibility of bus driverss. Journal of academia-industrial technology. 2010;11(11):4367-73.

18. Jeong KY, Kim SY. Effect of lumbar stabilizing taping on the electromyographic activation of trunk and gluteal muscles during one-leg standing. The journal of Korean academy of physical therapy science. 2010:23-32.

19. Kim KH. Effect of kinesio taping on the back of the paramedics. Department of Paramedic Science, Graduate School, Korea National University of Transportation. 2017.

20. Lee JE, Lee CH, Kwon OY, et al. Dynamic balance and muscle activity of the trunk and hip extensor following the wearing of pelvic compression belt. Physical Therapy Korea. 2015;22(1):53-5.

21. Jang HJ, Kim SY, Park HJ. Effects of the pelvic compression belt on trunk muscles activities during sit-to-stand, and stand-to-sit tasks. Physical Therapy Korea. 2013;20(1):1-9.

22. Park HK, Kim TH. Effect of pelvic tilting and the back-belt on electromyographic activity of erector spinae during lifting. The korea contents society. 2008;9(3):296-304. 